\title{
Frequency Regulation Provision Using Cross-Brand Bidirectional V2G-Enabled Electric Vehicles
}

Hashemi, Seyedmostafa; Arias, Nataly Banol; Bach Andersen, Peter; Christensen, Bjoern; Traholt, Chresten

\section{Published in:}

Proceedings of 2018 6th IEEE International Conference on Smart Energy Grid Engineering, SEGE 2018

Link to article, DOI:

10.1109/SEGE.2018.8499485

Publication date:

2018

Document Version

Peer reviewed version

Link back to DTU Orbit

Citation (APA):

Hashemi, S., Arias, N. B., Bach Andersen, P., Christensen, B., \& Traholt, C. (2018). Frequency Regulation Provision Using Cross-Brand Bidirectional V2̈G-Enabled Electric Vehicles. In Proceedings of 2018 6th IEEE International Conference on Smart Energy Grid Engineering, SEGE 2018 (pp. 249-254). [8499485] IEEE. https://doi.org/10.1109/SEGE.2018.8499485

\section{General rights}

Copyright and moral rights for the publications made accessible in the public portal are retained by the authors and/or other copyright owners and it is a condition of accessing publications that users recognise and abide by the legal requirements associated with these rights.

- Users may download and print one copy of any publication from the public portal for the purpose of private study or research.

- You may not further distribute the material or use it for any profit-making activity or commercial gain

- You may freely distribute the URL identifying the publication in the public portal 


\title{
Frequency Regulation Provision Using Cross-Brand Bidirectional V2G-Enabled Electric Vehicles
}

\author{
Seyedmostafa Hashemi \\ Center for Electric Power \\ and Energy (CEE) \\ Technical University of \\ Denmark \\ Copenhagen, Denmark \\ e-mail: \\ shtog@elektro.dtu.dk
}

\author{
Nataly Bañol Arias \\ Electrical Engineering \\ Department \\ Sao Paulo State University \\ São Paulo, Brasil \\ e-mail: \\ natycanta@aluno.feis.unes \\ p.br
}

\author{
Peter Bach Andersen \\ Center for Electric Power \\ and Energy (CEE) \\ Technical University of \\ Denmark \\ Copenhagen, Denmark \\ e-mail: \\ pba@elektro.dtu.dk
}

\author{
Bjoern Christensen \\ NUVVE Corporation \\ San Diego, CA, USA \\ e-mail: \\ bjoern@nuvve.com
}

\author{
Chresten Træholt \\ Center for Electric Power and Energy (CEE) \\ Technical University of Denmark \\ Copenhagen, Denmark \\ e-mail: ctr@elektro.dtu.dk
}

\begin{abstract}
With the increasing number of electric vehicles (EVs) in use, concern about their impact on the power quality of local distribution grids is also increasing. However, efficient control of state-of-the-art EVs and their supply equipment has a great potential not only to minimize the grid impact from EV integration, but also to provide desired services for system operators in renewable-based energy systems. This paper presents and analyzes the results from the demonstration of frequency-controlled normal operation reserve (FCR-N) that is among the primary frequency regulation services in the Nord Pool energy market. EVs from different EV manufacturers as well as advanced bidirectional DC chargers are implemented in the demonstration, which is the first vehicle-to-grid (V2G) demonstration in the Nordic area with commercially available components and cross-brand EVs. A centralized control method is implemented, and two-way communications links are established to send the control signals and receive the measured data on a second-by-second basis. The results associated with the operation of EVs with different battery capacities providing FCR-N are presented, and several parameters required for validating the quality of support for FCR-N are discussed based on the demonstration outcomes. The results confirm that V2G-enabled EVs are able to provide high quality and very fast responses, and pave the way for future renewable-based energy systems.
\end{abstract}

Keywords-electric vehicle; frequency regulation; frequency reserve; vehicle to grid; demonstration

\section{INTRODUCTION}

Renewable energy sources (RES) play an important role in designing future energy systems. Given a high share of renewables in power systems, the security of supply may deteriorate as regulating the generation-consumption becomes more critical with non-dispatchable and fluctuating renewables. On the basis of market structure and rules, transmission system operators (TSOs), independent system operators (ISOs) or other operating parties are responsible for administrating reserve power to guarantee the stability and security of power systems by maintaining the balance between electricity production and consumption.

An increase in the penetration of EVs, mainly motivated by environmental challenges and economic incentives, brings new concerns about the quality of services in electric distribution systems. These challenges include increasing the peak load, overloading grid components, and voltage violations [1]-[3], and several studies are conducted to deal with these challenges by proposing smart charging algorithms [4]-[6]. The joint operation of EVs and RES is also proposed in recent literature [7]-[9].

Due to the manageable nature of their loads, EVs, specifically vehicle-to-grid (V2G) enabled EVs can be used to support the grid by providing frequency regulation services to TSOs. A significant trend in recent literature is focused on the economic benefit for EVs providing frequency regulation. In [10] the authors perform economic analysis of EVs participating in frequency regulation markets, and in [11], certain strategies for the participation of EVs in frequency regulation markets are proposed. EV Frequency regulation markets in France and UK are explored in [12] and [13], respectively. Another study performed on the German market concluded that EVs' profit for participating in frequency regulation markets highly depends on the market conditions [14]. The participation of EVs in frequency regulation markets in North American systems are also studied in certain literature [15], [16]. Fast-response frequency regulation services by V2G-enabled EVs need technical verifications as well. However, the majority of the studies focused on the economic evaluations, and results 
associated with the real implementation of frequency regulation using V2G-enabled EVs are rarely presented.

This paper presents the results from the demonstration of frequency-controlled normal operation reserve (FCR-N), which is one of primary frequency regulation services in the Nord Pool energy market. EVs from Nissan, Mitsubishi Motors Corporation, and Groupe PSA as well as bidirectional DC chargers from Enel are used in the demonstration. A centralized control method based on a Nuvve platform is implemented, and two-way communications links are established. The results associated with the operation of a set of EVs providing FCR-N are presented and discussed. The work is done as a part of the Parker project [17], which deals with the implementation and validation of services that can be provided by V2G-enabled EVs contributing to renewable-based and fossil-fuel-free energy systems. An overview of the demonstration is shown in Fig. 1.

The technical specifications of FCR-N and an overview of the demonstration are presented in Section II. Frequency variations and challenges of EVs providing FCR-N are discussed in Section III. Results associated with the operation of three EVs with different battery capacities are presented and discussed in Section IV, including energy exchanged from and to the grid, EV battery state of charge (SoC) and depth of discharge (DoD) variations, delays and accuracy of response, and the preferred operating point (POP) adjustments. Finally, conclusions are provided in Section V.

\section{FREQUENCY-CONTROLLED NORMAL OPERATION} Reserve (FCR-N) Provision Using V2G-EnABLEd EVs

\section{A. Technical Specifications of FCR-N}

Europe is split into five regional groups by the European Network of Transmission System Operators (ENTSO-E) based on the synchronous areas (Continental Europe, Nordic, Baltic, Great Britain, and Ireland-Northern Ireland), without necessarily being synchronized with each other, and 2 voluntary Regional Groups (Northern Europe and Isolated Systems). ENTSO-E represents 43 TSOs from 36 countries. Region Nordic includes Denmark-East (DK2), Finland, Norway and Sweden [18].

According to Energinet [19], the Danish TSO, FCR-N is procured to ensure a balance between consumption and generation, and it automatically stabilizes the frequency at 50 Hz. Only symmetrical bids are allowed, meaning that upward and downward regulation reserves are procured together. The TSOs within the Nordic synchronous area are jointly responsible for the supply of FCR-N, which is 600 MW. At frequency deviations of between 0 and $100 \mathrm{mHz}$, as a minimum the reserve has to be supplied linearly. The activated reserve must be supplied within 150 seconds. More details can be found in [19].

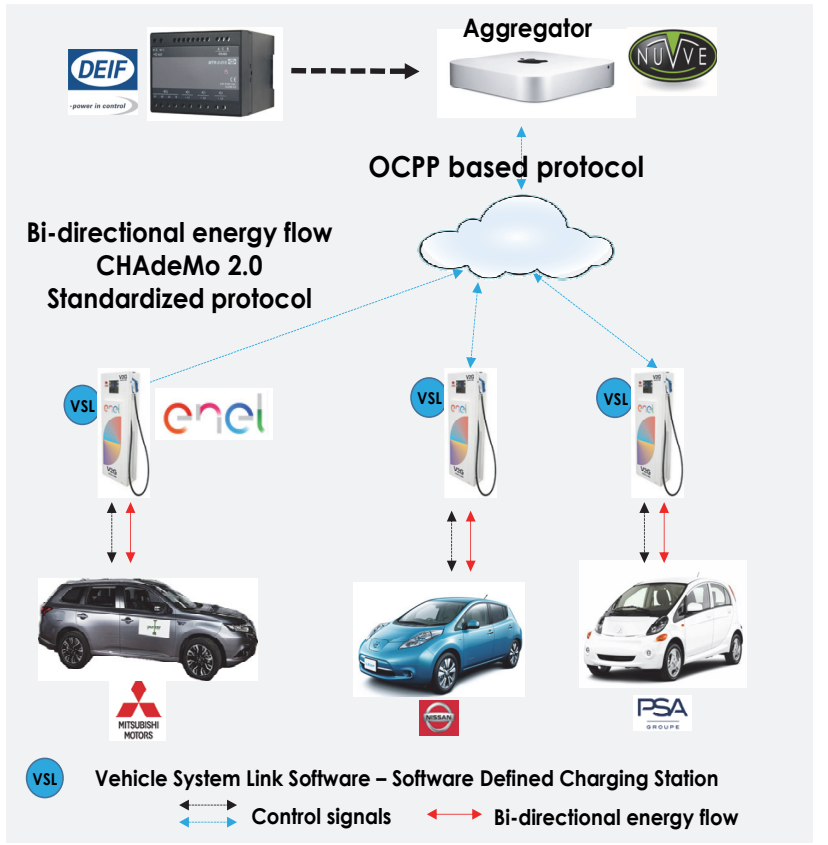

Figure 1. An overview of the demonstration. EVs are located in different places at the Technical University of Denmark.

\section{B. Provision of FCR-N Using V2G-Enabled EVS}

Both unidirectional and bidirectional V2G-enabled EVs are able to participate in the frequency regulation services. However, EVs with unidirectional chargers can only change their charging power set points, similar to the controllable loads. Therefore their participation in the frequency regulation market is limited to a short period of time with a low bidding power. As a result, the profit for market participation may not be considerable. V2G-enabled EVs act similar to the battery energy storage systems and can charge and discharge their batteries based on the frequency variations. If the POP is zero, EV battery is discharged when upward regulation is required, and it is charged when downward regulation is required. Considering frequency variations, the EV operation follows the FCR-N droop as shown in Fig. 2.

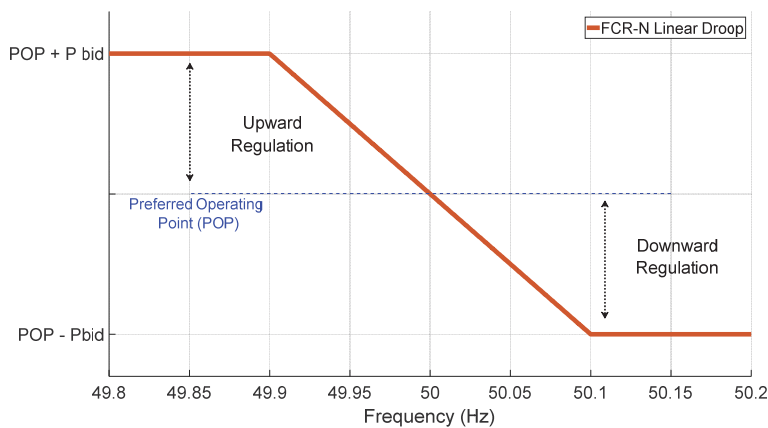

Figure 2. The linear droop of frequency-controlled normal operation reserve (FCR-N) and the associated V2G-enabled EV operating points 
The demonstration is based on a Nissan Leaf with the battery capacity of $30 \mathrm{kWh}$, a Peugeot iOn with the battery capacity of $16 \mathrm{kWh}$ and a Mitsubishi Outlander with the battery capacity of $12 \mathrm{kWh}$. Enel V2G chargers with the rating power of around $10 \mathrm{~kW}$ are used in the demonstration. Nuvve platform provides a centralized control mechanism and two-way communications links; they are established for sending control commands and receiving measured data in a second-by-second basis. Based on the frequency data, bidding power and SoC of EVs, Nuvve aggregator sends a control signal to the EV chargers. The EV chargers communicate to the EVs to send the charging or discharging set points and receive several data such as SoC from EVs. The EV chargers send the data received from EVs and local measurement units to the Nuvve aggregator. The data are stored in the Nuvve platform on a second-by-second basis. An overview of the demonstration is shown in Fig. 1.

\section{FREQUENCY VARIATIONS AND CHALLENGES OF EVS PROVIDING FCR-N}

The frequency fluctuates around the nominal frequency, which is $50 \mathrm{~Hz}$ in Europe, and it is expected that the duration of over frequencies and under frequencies are short. However, the frequency may be higher or lower than the nominal frequency for an extended period of time, specifically in renewable-based power systems. EVs have a limited battery capacity and it is feasible that the EV battery is fully charged or discharged during the service provision period. Under this condition the EV cannot provide the promised service for the entire period.

\section{A. Frequency Analysis}

Frequency is very variable and unpredictable. The frequency analysis of the Region Nordic during three days in September 2017 is shown in Fig. 3. Using statistical analysis tools, it is found that a normal distribution can represent the frequency distribution. Fig. 3 shows the frequency probability density function (pdf). The normal distribution function has a mean value of $50.003 \mathrm{~Hz}$ and a standard deviation of $0.0455 \mathrm{~Hz}$. Fig. 4 shows the hourly average for over and under frequencies. As can be seen, the average frequency is not hourly biased and it may happen that for more than four consecutive hours the average frequency is higher or lower than $50 \mathrm{~Hz}$.

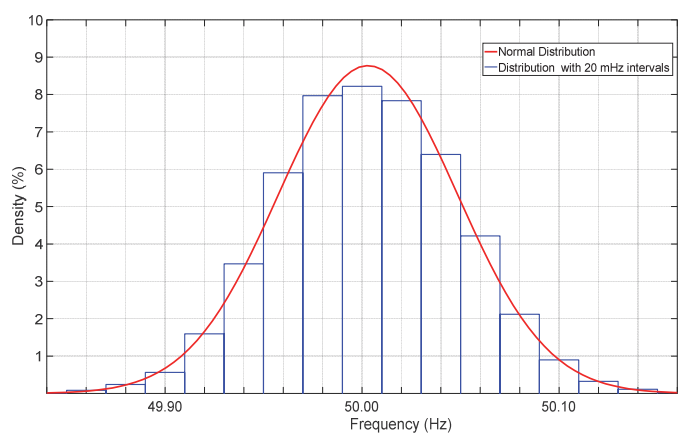

Figure 3. Frequency distribution with intervals of $20 \mathrm{mHz}$ for 3 days.

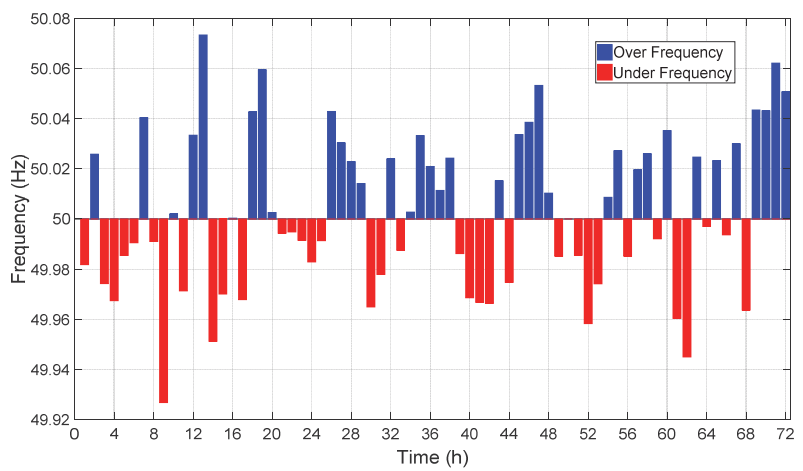

Figure 4. Hourly average frequency for 3 days.

To explain more, the periods of over and under frequencies in time intervals of one minute are shown in Fig. 5. As can be seen, most of the time the over and under frequencies have durations less than 5 minutes. However, it is still possible to have over or under frequencies last for more than one hour, even during this short period of three days. It was found that the longest duration of over frequencies was around 67 minutes, and the longest duration of under frequencies was around 56 minutes.

\section{B. Unavailability of Service}

To estimate the unavailability period of FCR-N service provision using EVs, a set of simulations are performed considering EVs used in the demonstration. The simulations are run considering $50 \%$ initial $\mathrm{SoC}$, bidding power equal to $10 \mathrm{~kW}$, and the usable capacity for all EVs equal to $70 \%$ of the battery capacity. The battery is charged or discharged according to the frequency signal, and if the battery is fully charged or discharged the $\mathrm{EV}$ is no longer able to provide the service. Fig. 6 shows the SoC of the three EVs. As can be seen, during a considerable period of time the EVs are not able to provide frequency regulation. The duration of unavailability is around $18 \%, 12 \%$ and $5 \%$ for outlander, iOn, and Leaf, respectively. One solution is to reduce the bidding power; however, the profits of EV owners reduce considerably. To decrease the unavailability period and also improve the life-span of EV batteries smart methods should be applied.

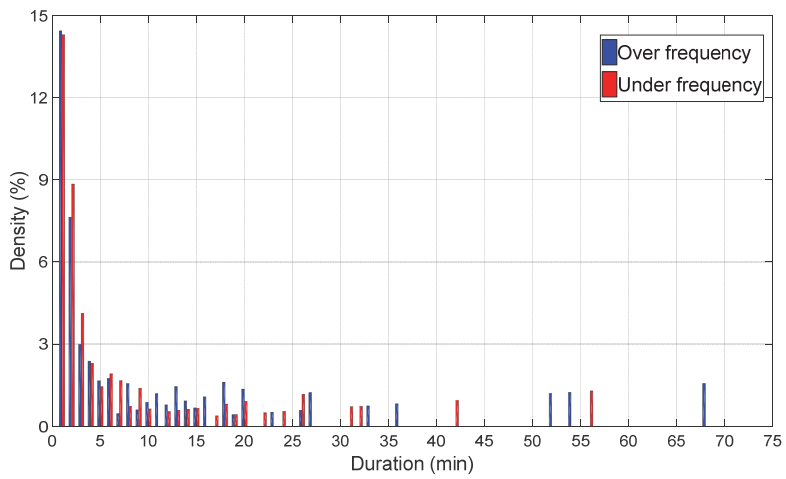

Figure 5. Under and over frequency durations (1-minute intervals). 


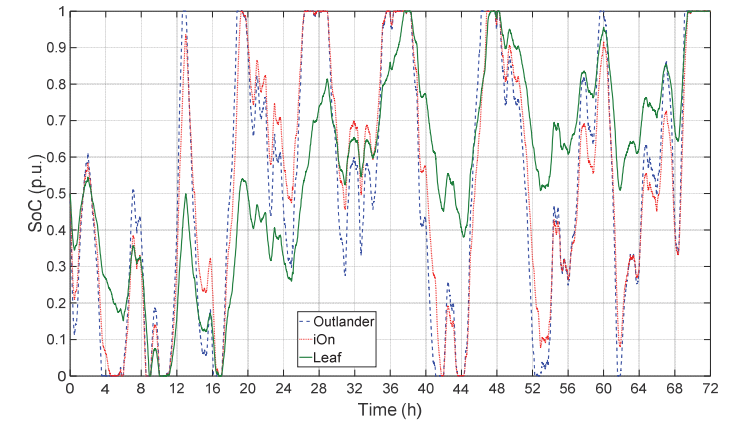

Figure 6. Simulated SoC of the EVs providing FCR-N during 3 days.

In the demonstration, adjustments are performed on the POP to ensure that the SoC levels of EV batteries allow regulation services at longer periods. The POP adjustments are activated when the battery SoC reach values higher than around $70 \%$ or less than around $40 \%$ of the battery capacity, and avoid EVs to be fully charged or discharged during the service provision period.

\section{DEMONSTRATION RESUlts}

As mentioned before, three EVs with different battery capacities from different manufacturers are used in the demonstration. To decrease the battery degradation, the usable battery capacity is considered to be around 70 percent of the nominal battery capacity. Several parameters are stored in the Nuvve aggregator platform, and certain relevant parameters are presented and discussed in this part.

\section{A. Frequency Variations and the Power Requested}

The power requested by the TSO/aggregator depends on the frequency signal and the droop control associated with the FCR-N. Fig. 7 depicts the power requested and the frequency signal. These power set points are implemented to the $\mathrm{iOn}$; however, if the $\mathrm{SoC}$ is within the predefined boundaries and POP is not activated, the power set points are the same for all EVs. As can be seen, when the frequency is lower than $50 \mathrm{~Hz}$, positive power is required, which means that the charger is controlled to inject power to the grid and $\mathrm{EV}$ works in the $\mathrm{V} 2 \mathrm{G}$ mode. On the other hand, when the frequency is higher than $50 \mathrm{~Hz}$, negative values of power are requested, which means that the EV battery is charged. If the POP is activated, the power requested values move up or down according to the POP values.

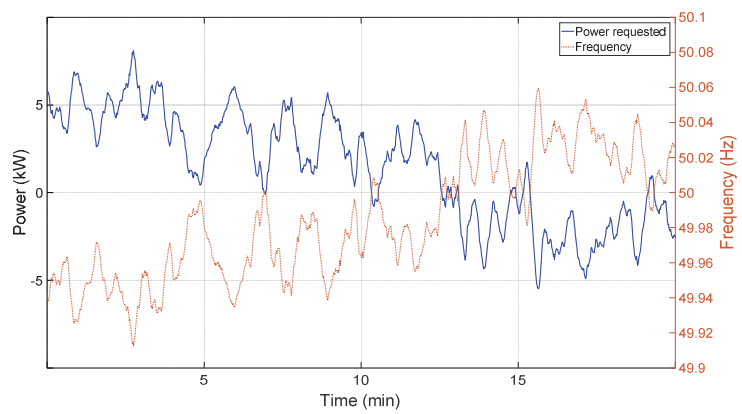

Figure 7. The power requested for iOn and the related frequency signal.

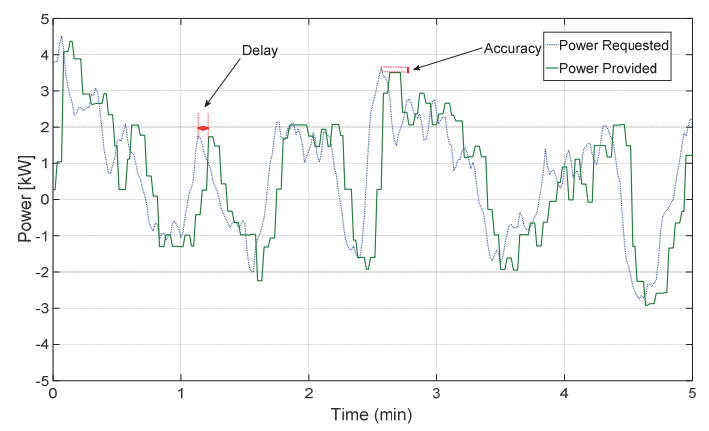

Figure 8. The power requested and the power provided for iOn.

\section{B. Delays and Accuracy of Response}

The power requested by the TSO/aggregator and the power provided by the EVs follow the same pattern. However, there may be certain small differences in terms of delay and accuracy. The delays are mainly because of delay in the EV and EV charger response, measurement units' delays and communication delays; the latter includes sending commands to the charger, receiving the measured data from the charger and data logging. The constraints set to the equipment such as power steps of the charger, needs for compensation of charger self-consumption and the measurement errors are the main sources of the response inaccuracy. Fig. 8 shows the power requested and the power provided based on one-second-resolution data for five minutes of operation. As can be seen, the power provided has a delay, and there are small differences between the magnitude of the power requested and the power provided.

By applying statistical and correlation analysis, it is found that the delay is around 6 seconds, with the accuracy of around $98 \%$. Defining the response time as the time elapsed between dispatching the power requested by the aggregator to the time when the DC charger provides the power requested, the response time is less than the calculated 6 seconds. It is because the calculated delay includes a delay from measurement units that typically perform analysis on the measured data, communication delay associated with sending the measured data to the aggregator, and a delay as a result of data logging. Considering these delays, the expected response time is around half of this calculated value and is approximately around 3 seconds. The analysis is performed for all EVs, and it is concluded that the response time and accuracy of response are almost the same for the three EVs.

\section{Energy Exchanged, SoC and the POP Set Points}

The SoC, hourly energy exchange and the POP for iOn are shown in Fig. 9. As can be seen, the SoC changes frequently, and there are several small cycles in addition to the larger DoDs. When the SoC reaches higher than around $70 \%$ or less than around $40 \%$ of the battery capacity, the POP is activated in order to bring the SoC to the predefined boundaries. For iOn, the POP is activated around $22 \%$ of the time; the maximum value of POP is around $6 \mathrm{~kW}$ and the minimum is around $-10 \mathrm{~kW}$. 

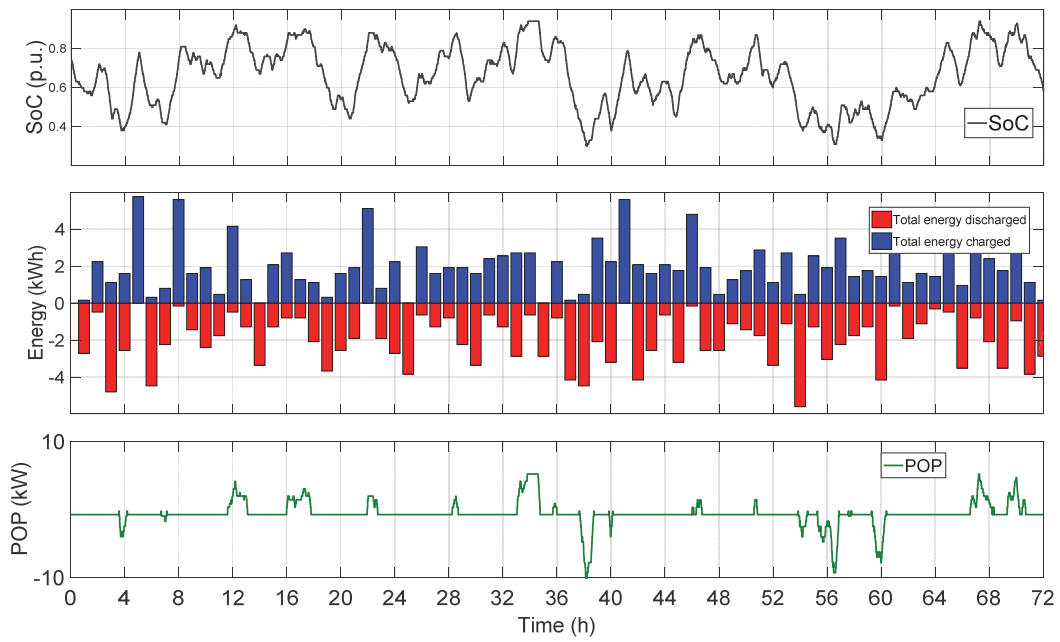

Figure 9. SoC, hourly energy exchange and the POP for EV-iOn (72 hours of operation).

In addition, the total energy charged and discharged during each hour is shown in Fig. 9. As can be seen, the energy exchanged differs hour by hour. The energy exchanged mainly depends on the frequency signal; it can also be clarified by comparing Fig. 9 with Fig. 4. However, high or low SoCs activate the POP mechanism and affect the energy exchanged. The energy exchanged is an important parameter in evaluation of FCR-N; the revenue for the FCR-N service provision is partly calculated based on the net energy exchanged, and the battery degradation can be estimated using the energy exchanged in certain simplified degradation models.

\section{Effects of Battery Capacity on the Unavailability of Service and Depth of Battery Cycles}

As mentioned before, EVs with the battery capacities of 12,16 and $30 \mathrm{kWh}$ are used in the demonstration. The bidding power for all EVs is $9.25 \mathrm{~kW}$. All EVs can potentially earn almost similar revenues for participation in FCR-N market; the small difference is about the value of energy exchanged. However, as mentioned before, the duration of unavailability is around $18 \%, 12 \%$ and $5 \%$ for outlander, iOn, and Nissan, respectively, if the POP is not implemented. The unavailability period can highly affect the net profit. In addition, the unavailability periods of more than $5 \%$ are probably not acceptable for certain TSOs; therefore, as one of the solutions the bidding power should be decreased. Another solution that is implemented in the demonstration is the POP mechanism.

The durations of POP activation in time intervals of 15 minutes are shown in Fig. 10. As can be seen, the POP is activated more frequently for the EVs with smaller battery capacities. For Outlander, iOn and Leaf the POP activation period is around $34 \%, 22 \%$ and $14 \%$ of the total operation period, respectively. Although currently there is no limitation for activation of POP, if the POP values are comparable with the bidding power the probability of service unavailability increases. The unavailability period is defined in this work as the percentage of time that the power requested cannot be provided as a result of EV charger limitations.

According to the analysis carried out on the power requested and the power provided of EVs, these unavailability periods are $2.4 \%, 1.8 \%$ and $0.4 \%$ for the outlander, iOn and Leaf, respectively. The unavailability periods are considerably decreased compared to the previous cases without POP implementation, and it is less than $2.5 \%$ for all EVs. On the basis of the results, it can be concluded that an EV with small battery capacity has a higher chance of service unavailability. Therefore, if unavailability period is not acceptable by the TSOs, the bidding power should be decreased. If EVs are operated in aggregated mode or as a fleet the unavailability period can be reduced considerably.

In addition to an increase in the probability of service unavailability, the battery degradation has to be investigated when implementing small EV batteries with a high bidding power. Fig. 11 shows a comparison between the numbers of cycles in terms of DoD for the three EVs. The DoDs between $1 \%$ and $100 \%$ are classified in the intervals of $10 \%$, and using the rain-flow counting algorithm the number of cycles within each DOD intervals is calculated. According to the results, smaller EV batteries have deeper cycles. For instance, smaller DoDs happen for the Leaf that has the highest battery capacity, and outlander with the smallest battery capacity has the deepest cycles' depth. It is known that smaller DoDs usually result in less battery degradation compared to deep cycles; therefore, an EV with smaller battery capacity has potentially higher battery degradation. The battery replacement cost has to be considered in the economic calculations of frequency regulation, if the battery life span becomes less than its expected life as a result of frequency regulation. It is worth mentioning that there are no occurrences of cycle depth greater than $40 \%$ DoDs for all three EVs. 

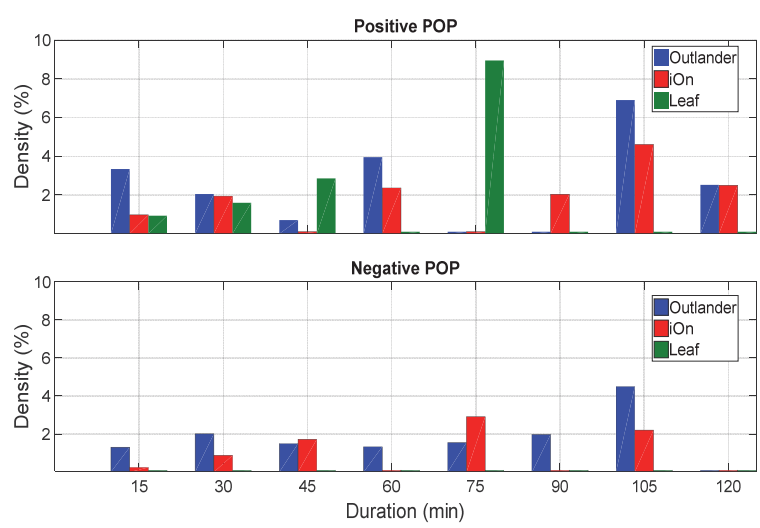

Figure 10. The durations of POP activation in time intervals of 15 minutes.

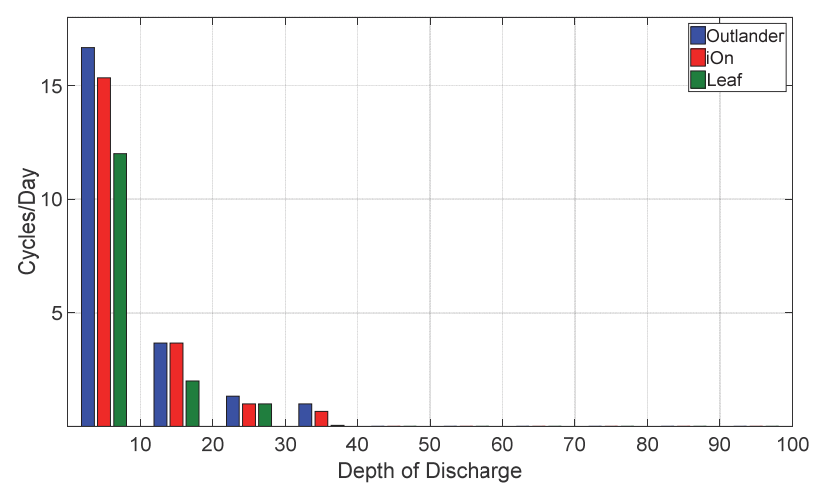

Figure 11. Number of cycles in $10 \%$ DoD intervals for all EVs.

\section{CONCLUSIONS}

The results from the demonstration of frequencycontrolled normal operation reserve (FCR-N) were presented and analyzed in this paper. Three EVs with different battery capacities and advanced bidirectional chargers were implemented and centrally controlled. The results indicated that V2G-enabled EVs from different manufacturer are able to provide fast and accurate responses. The response time was estimated less than 5 seconds, and the accuracy of response was around $98 \%$ for all EVs, which can even be improved by software and hardware adjustments. In addition, even the EV with the smallest battery capacity of $12 \mathrm{~kW}$ was able to provide frequency regulation service with the bidding power of around $9 \mathrm{~kW}$ limited by the capacity of utilized chargers; however, the probability of service unavailability was more when EVs with smaller battery capacities were used. Moreover, the DoDs were less than $40 \%$ for all EVs; however, EVs with smaller battery capacities had deeper cycles that may result in higher battery degradation.

\section{ACKNOWLEDGMENT}

This work is supported by the Danish project "Parker" under ForskEL contract no. 2016-1-12410.

\section{REFERENCES}

[1] A. Dubey and S. Santoso, "Electric Vehicle Charging on Residential Distribution Systems: Impacts and Mitigations," IEEE Access, vol. 3, pp. 1871-1893, 2015.

[2] J. Xiong, K. Zhang, Y. Guo, and W. Su, "Investigate the impacts of PEV charging facilities on integrated electric distribution system and electrified transportation system," IEEE Trans. Transp. Electrif., vol. 1, no. 2, pp. 178-187, Aug. 2015.

[3] S. Hashemi, G. Yang, J. Østergaard, S. You, and S.-T. Cha, "Storage application in smart grid with high PV and EV penetration," in 2013 4th IEEE/PES Innovative Smart Grid Technologies Europe, ISGT Europe 2013, 2013.

[4] G. Lacey, G. Putrus, and E. Bentley, "Smart EV charging schedules: supporting the grid and protecting battery life," IET Electr. Syst. Transp., vol. 7, no. 1, pp. 84-91, 2017.

[5] J. Quiros-Tortos, L. F. Ochoa, S. W. Alnaser, and T. Butler, "Control of EV Charging Points for Thermal and Voltage Management of LV Networks," IEEE Trans. Power Syst., vol. 31, no. 4, pp. 3028-3039, Jul. 2016.

[6] E. Veldman and R. A. Verzijlbergh, "Distribution Grid Impacts of Smart Electric Vehicle Charging From Different Perspectives," IEEE Trans. Smart Grid, vol. 6, no. 1, pp. 333-342, Jan. 2015.

[7] S. Hashemi and J. Østergaard, "Methods and strategies for overvoltage prevention in low voltage distribution systems with PV," IET Renew. Power Gener., vol. 11, no. 2, Feb. 2017.

[8] H. N. T. Nguyen, C. Zhang, and A. Mahmud, "Optimal coordination of G2V and V2G to support power grids with high penetration of renewable energy," IEEE Trans. Transp. Electrif., vol. 1, no. 2, pp. 188-195, 2015.

[9] E. Akhavan-Rezai, M. F. Shaaban, E. F. El-Saadany, and F. Karray, "Managing demand for plug-in electric vehicles in unbalanced LV systems with photovoltaics," IEEE Trans. Ind. Informatics, vol. 13, no. 3, pp. 1057-1067, Jun. 2017.

[10] A. O. David and I. Al-Anbagi, "EVs for frequency regulation: cost benefit analysis in a smart grid environment," IET Electr. Syst. Transp., vol. 7, no. 4, pp. 310-317, 2017.

[11] S. Han and K. Sezaki, "Estimation of achievable power capacity from plug-in electric vehicles for V2G frequency regulation: Case studies for market participation," IEEE Trans. Smart Grid, vol. 2, no. 4, pp. 632-641, 2011.

[12] P. Codani, M. Petit, Y. Perez, P. Codani, M. Petit, Y. Perez, P. Codani, and M. Petit, "Participation of an electric vehicle fleet to primary frequency control in France To cite this version: frequency control in France," Int. J. Electr. Hybrid Veh., vol. 7, no. 3, pp. 233-249, 2016.

[13] R. Gough, C. Dickerson, P. Rowley, and C. Walsh, "Vehicle-togrid feasibility: A techno-economic analysis of EV-based energy storage," Appl. Energy, vol. 192, pp. 12-23, 2017.

[14] T. Brandt, S. Wagner, and D. Neumann, "Evaluating a business model for vehicle-grid integration: Evidence from Germany," Transp. Res. Part D Transp. Environ., vol. 50, pp. 488-504, 2017.

[15] N. DeForest, J. S. MacDonald, and D. R. Black, "Day ahead optimization of an electric vehicle fleet providing ancillary services in the Los Angeles Air Force Base vehicle-to-grid demonstration," Appl. Energy, 2017.

[16] S. Vandael, T. Holvoet, G. Deconinck, S. Kamboj, and W. Kempton, "A comparison of two V2G mechanisms for providing ancillary services at the University of Delaware," 2013 IEEE Int. Conf. Smart Grid Commun., no. October, pp. 211-216, 2013.

[17] "Parker Project." [Online]. Available: http://parker-project.com/.

[18] "Regional Groups." [Online]. Available: https://www.entsoe.eu/about/system-operations/.

[19] "Rules and Regulations in the Danish Electricity Market." [Online]. Available: https://en.energinet.dk/Electricity/Rules-andRegulations. 